\title{
MUJERES Y POLÍTICA. Un PANORAMA SOBRE LA ADOPCIÓN DE LAS CUOTAS DE GÉNERO Y SUS EFECTOS EN AMÉRICA LATINA Y COLOMBIA*
}

María InÉs Tula ${ }^{* *}$

\section{Resumen}

Hace ya varios años, los análisis sobre la participación política de las mujeres advertían una muy baja presencia de estas en los distintos parlamentos del mundo. El diagnóstico de la subrepresentación femenina fue una señal de alerta para los diferentes organismos internacionales, los cuales, a partir de sucesivas convocatorias, comenzaron a planificar una revisión de la situación para que los diversos países se comprometieran a adoptar medidas tendientes a modificarla. El presente trabajo tiene como fin describir el panorama actual sobre mujeres y política en América Latina, con especial atención al caso colombiano, centrándose fundamentalmente en la adopción de cuotas de género como estrategias de discriminación positiva que contribuyan a una mayor participación de las mujeres en la política de la región.

Palabras clave: mujeres, participación política, cuota de género, América Latina, Colombia.

* Este trabajo fue elaborado para ser discutido en el marco del foro "Poder, representación y equidad: retos para la participación política de las mujeres", organizado por el Programa de las Naciones Unidas para el Desarrollo (PNUD); la Organización de Estados Americanos (OEA); el Instituto Holandés para la Democracia Multipartidaria (NIMD) y la Facultad de Finanzas, Gobierno y Relaciones Internacionales de la Universidad Externado de Colombia, el 22 de octubre de 2014. Además, una versión previa del mismo será publicada por PNUD Colombia.

** Doctora en Derecho. Profesora regular en la carrera de Ciencia Política de la Universidad de Buenos Aires (UBA) e investigadora de carrera en el Consejo Nacional de Investigaciones Científicas y Técnicas (CONICET), Buenos Aires (Argentina).inestula@yahoo.com

Recibido: 20 de enero de 2015 / Modificado: 2 de febrero de 2015 / Aceptado: 9 de febrero de 2015.

Para citar este artículo

Tula, M. I. (2015). Mujeres y política. Un panorama sobre la adopción de las cuotas de género y sus efectos en América Latina y Colombia. OPERA, 16, pp. 9-33. DOI: 10.18601/16578651.n16.03 
WOMEN AND POLITICS. A VIEW ON THE ADOPTION OF GENDER QUOTAS AND ITS EFFECT ON LATIN AMERICA AND COLOMBIA

\section{Abstract}

For a number of years now, analyses of the political participation of women have warned of a very low presence of these in the various parliaments of the world. The diagnosis of female underrepresentation was a warning sign for different international organisms, which initiating from successive calls started to plan a review of the situation so that various countries would commit themselves to adopt measures to modify it. This paper has the goal of describing the current outlook of women and politics in Latin America, with special attention paid to the Colombian case, focusing fundamentally on the adoption of gender quotas as a strategy of positive discrimination that might contribute to a larger participation of women in the politics of the region.

Key words: Women, polítical participation, gender quota, Latin America, Colombia.

\section{INTRODUCCIÓN}

Hace ya varios años, los análisis sobre la participación política de las mujeres advertían una muy baja presencia de estas en los distintos parlamentos del mundo. El diagnóstico de la subrepresentación femenina fue una señal de alerta para los diferentes organismos internacionales, los cuales, a partir de sucesivas convocatorias, comenzaron a planificar una revisión de la situación para que los diversos países se comprometieran a adoptar medidas tendientes a modificarla.

¿Cómo garantizar la igualdad? El punto de partida institucional tuvo su origen en las Recomendaciones y Plataformas de Acción elaboradas por las Naciones Unidas con el fin de homogeneizar el diseño normativo de las legislaciones sobre igualdad de oportunidades. Tanto la Convención sobre la Eliminación de Todas las Formas de Discriminación contra la Mujer en 1979, como las posteriores Conferencias Mundiales de Nairobi (1985) y Beijing (1995) marcaron este camino. En Beijing fue donde se reconoció que la atención debía centrarse en el concepto de género, al entender que toda la estructura de la sociedad y las relaciones entre hombres y mujeres debían ser reevaluadas. Únicamente mediante esa reestructuración de la sociedad y de sus instituciones sería posible potenciar el papel de las mujeres hacia un plano igualitario. Así, se reafirmó la idea de que los derechos de las mujeres eran derechos humanos, y que la igualdad entre los géneros era una cuestión de interés universal y de beneficio para todos. Esta postura fue respaldada en 2000 cuando se convalidaron los ocho propósitos que hoy constituyen los Objetivos de Desarrollo del Milenio (oDM), y que en su punto 3 proyecta avanzar en la igualdad de géneros y en la autonomía de las mujeres a partir de su empoderamiento.

En 2007, durante la x Conferencia Regional de la Mujer de América Latina y el Caribe organizada por la Comisión Económica para América Latina y el Caribe (CEPAL), desarrollada en Ecuador, se firmó el Consenso de Quito. Allí se confirmaron todos los acuerdos 
internacionales previos y se avanzó en la necesidad de establecer la paridad entre los géneros como meta. En 2010, en la XI Conferencia Regional sobre la Mujer de América Latina y el Caribe, efectuada en Brasil, se ratificó el Consenso de Quito y su plena vigencia. En la ciudad de Brasilia se evaluaron los avances logrados en diferentes planos y se destacaron los progresos realizados en la adopción de marcos legales igualitarios para la construcción y el fortalecimiento de la igualdad entre hombres y mujeres.

No obstante estos importantes y grandes adelantos, se advirtió sobre ciertos obstáculos todavía presentes en varios países y en la necesidad de redoblar los esfuerzos para eliminar la violencia y determinadas prácticas que limitan e impiden el desarrollo de la plena igualdad entre géneros. Recae, entonces, una doble responsabilidad. Por un lado, sobre el Estado, la de promover y garantizar mayores condiciones de igualdad en los países, y, por el otro, recae sobre la sociedad la responsabilidad de controlar su puesta en marcha y su correcto funcionamiento. La creación de "observatorios" ha sido decisiva a la hora de monitorear y supervisar el alcance de todas estas medidas con datos precisos sobre su cumplimiento y efectividad.

Con este propósito, el presente trabajo tiene como fin describir el panorama actual sobre mujeres y política en América Latina, con especial atención al caso colombiano. Para fines prácticos, este trabajo se divide en cuatro secciones. Una primera que describe sintéticamente qué se entiende por cuotas de género y sus diferentes modalidades. Un segundo apartado que sintetiza los efectos de las cuotas de género y leyes de paridad en la región durante el periodo 1991-2014. En tercer lugar, se analiza el caso particular de Colombia con la aplicación de la Ley 1475/11 y, por último, se hacen una serie de recomendaciones orientadas a fortalecer la participación política de las mujeres en Colombia y mejorar las condiciones para su real acceso a la representación.

\section{¿QUÉ SON LAS CUOTAS DE GÉNERO? ¿POR QUÉ Y PARA QUÉ?}

Las "cuotas" o "cupos" para las mujeres son una forma de acción afirmativa admitida en diferentes países del mundo para superar los obstáculos que les impiden ingresar en la política de igual modo que sus pares masculinos (Larserud y Taphorn, 2007, p. 9). Constituyen medidas compensatorias y redistributivas tendientes a revertir situaciones de desigualdad. A través de ellas, se posibilita una gradual inclusión de los grupos históricamente marginados en las diferentes instituciones representativas o lugares estratégicos de toma de decisión.

A grandes rasgos, en el ámbito internacional, los sistemas de cuotas presentan tres modalidades en lo que se refiere a su aplicación en los órganos de representación colegiados. Por un lado, las cuotas legales se basan en un dispositivo de normas jurídicas tales como constituciones nacionales o leyes que disponen de manera oficial cómo debe aplicarse esta exigencia en un proceso electoral. Su mayor efectividad se logra cuando estas son obligatorias para todos los partidos políticos y establecen una severa sanción por su incumplimiento como, por ejemplo, la no oficialización de las listas en las elecciones generales. 
Por otro lado, están las cuotas voluntarias, también denominadas "cuotas partidistas", porque han sido incorporadas en los estatutos internos de los partidos políticos para promover espacios de interacción entre géneros. Esta segunda modalidad ha quedado supeditada a la decisión de los propios partidos para fijar, fomentar y garantizar la postulación de un determinado número o proporción de mujeres dentro y fuera de la organización, tanto en puestos jerárquicos partidarios como en candidaturas para cargos públicos representativos.

Y, por último, están los escaños reservados que presentan un porcentaje o número fijo determinado de escaños parlamentarios para ser ocupados por mujeres.

Si bien en los tres casos se busca promover la participación y el acceso a la representación de las mujeres a través de medidas concretas, su anclaje ha sido diferente en distintas regiones del mundo. Según Krook (2008), las cuotas legales se han difundido principalmente en América Latina en los años noventa como porcentajes mínimos de representación por género en las listas partidistas que se oficializan en una elección para cargos electivos representativos. En algunos casos, han tenido un carácter propositivo no vinculante, limitando así su impacto a la decisión de los propios partidos en aplicar esta medida. Por su parte, las cuotas partidistas se han desarrollado más favorablemente en Europa desde principios de los años setenta, originalmente en los partidos políticos de izquierda, y los escaños reservados se han concentrado de manera especial en los países de África, Asia y el Medio Oriente.

\section{¿Por qué se sancionaron en América Latina?}

La inclusión tardía de las mujeres en la ciudadanía a través del reconocimiento del sufragio activo no redundó en una participación equitativa en los procesos de decisión. En consecuencia, la ausencia de mujeres en los procesos y procedimientos de toma de decisiones se consideró como un déficit importante de las democracias. La sola incorporación de la igualdad de género como premisa en los textos normativos no fue suficiente para que su cumplimiento se hiciera efectivo o tuviera un impacto real.

Con este argumento se buscó la aplicación de las acciones afirmativas para que rompieran el desequilibrio existente en las sociedades. Estas son herramientas que garantizan el principio de igualdad a través de la reparación de históricos tratos desventajosos que han tenido las mujeres. Dicho en otros términos, se trata de desterrar los privilegios que han ido erosionando el principio de igualdad cuando por diversos motivos la sobrecarga o el exceso de un derecho para unos (privilegios) conllevó una privación de ese derecho para otros (desventajas) (Cobo, 2009).

Por tanto, las acciones afirmativas representan un conjunto de medidas que promueven y generalizan la justicia distributiva frente a viejas situaciones de discriminación (Sartori, 1990). Y las cuotas de género se sustentan en el hecho de que las mujeres ven obstaculizado el ejercicio de su derecho a ser representantes en condiciones equivalentes de competitividad, como consecuencia de 
la histórica discriminación y subordinación sociocultural (Archenti, 2002).

\section{¿Para qué sirven?}

Con el fin de corregir este déficit en las democracias, las cuotas de género se sancionaron con el objetivo de conseguir una mayor presencia política de las mujeres y una mayor movilización de estas en los órganos de representación. Se orientan a disminuir la brecha entre géneros en el acceso a la representación buscando así garantizar un resultado más equitativo.

A diferencia de otras estrategias institucionales incorporadas como políticas públicas o desarrolladas como unidades de ejecución específicas para las mujeres en órganos decisorios, las cuotas de género fueron la medida más eficaz en términos de ampliación de los márgenes de representación por género al incrementar de manera rápida $\mathrm{y}$ - en corto plazo- la participación femenina en la composición de las legislaturas. La postulación de mujeres en las diversas listas electorales les proporcionó mayor visibilidady naturalizósu ejercicio por fuera del ámbito privado.

La incorporación de estas cuotas legales en los distintos países de América Latina desde principios de los años noventa incrementó sustantivamente el número de legisladoras. Sus efectos se perciben cuando se destaca a este subcontinente como la segunda región del mundo con más mujeres en sus parlamentos
(Cámaras Únicas o Bajas) con 25,6\% después de los países nórdicos, los cuales ostentan $42,1 \%$ (IPU, 2014) ${ }^{1}$. A su vez, un mayor número de mujeres en las legislaturas significó también un avance hacia la equidad de género al interior de las asambleas legislativas dado que promocionó el reconocimiento a nivel social, político y cultural de las diferencias de género a través de una ascendente presencia de mujeres ocupando espacios políticos tradicionalmente masculinos, y permitió un mayor contacto entre aquellas que ocupan cargos legislativos y las mujeres organizadas de la sociedad civil intensificando el vínculo de representación (Archenti y Tula, 2008).

Como última cuestión, los países que incorporaron cuotas legales resultaron más permeables a la emergencia de nuevos liderazgos o a la consolidación de trayectorias políticas ya iniciadas. Al introducirse esta oportunidad institucionalizada en los sistemas políticos, estos se vuelven más receptivos a nuevas postulaciones. Por ejemplo, desde 2005 cuatro mujeres han logrado ocupar el cargo de presidente de la Nación en América Latina de manera simultánea: Michelle Bachelet en Chile (2006-2010/2014-2018), Cristina Fernández de Kirchner en Argentina (2007-2011/2011-2015), Laura Chinchilla en Costa Rica (2010-2014) y Dilma Rousseff en Brasil (2010-2014/2014-2018). Tres de las cuales, además, han logrado reelegirse en el cargo. En Argentina, una mujer alcanzó el cargo de gobernadora provincial por primera

1 Inter-Parliamentary Union. Women in National Parliaments. En http://www.ipu.org/wmn-e/world.htm 
vez en 2007 —desde el inicio de la democracia en 1983 - para luego hacia 2014 sumar dos ejecutivos provinciales más ${ }^{2}$.

Un efecto cualitativo adicional ha sido la incorporación de regulaciones similares en las ramas del poder judicial y en algunas organizaciones sindicales donde la subrepresentación de mujeres también era alta.

\section{¿Cómo comprenderlas?}

La justificación de este tipo de medidas posee un interés social y otro político-institucional. Las acciones afirmativas no solo muestran la diversidad que debiera existir en una comunidad (que refleje el pluralismo de la sociedad), sino también busca corregir las ausencias, en este caso, de las mujeres en posiciones de poder. Y ambas cuestiones solo pueden lograrse si las mujeres están realmente incluidas en la sociedad (es decir, no solo a través del aspecto formal). En esta dirección, las acciones afirmativas no violan el principio de igualdad (el formal) sino, por el contrario, lo fortalecen porque garantizan la inclusión de las mujeres en la práctica, en la realidad cotidiana (Archenti y Tula, 2011).

Un argumento muy común para deslegitimar los resultados de las cuotas de género es el que sostiene que las mujeres deben ocupar cargos en las listas por su capacidad y no como un efecto legal de su aplicación. Sin embargo, esta apreciación no es utilizada con el mismo rigor para los candidatos hombres, quienes sí gozarían de esta cualidad de manera incuestionable. Al respecto, varios estudios señalan que las mujeres presentan igual o mejor calificación que los hombres al momento de ser electas pero se diferencian notoriamente cuando se compara entre ambos géneros la experiencia política o el capital político acumulado (Johnson, 2014; Schmidt, 2014). La respuesta a esta brecha debe buscarse en el acceso tardío de las mujeres en política, como también, cuando se reconoce que este ha sido un ámbito tradicionalmente hostil previo a las cuotas.

Asimismo, la persistencia de una cultura política con rasgos patriarcales en América Latina continúa siendo un obstáculo para su efectividad. Muchas de estas barreras informales se visualizan en la dinámica interna de los partidos políticos cuando, por ejemplo, se designan candidatas con bajos niveles de autonomía política pero con grandes garantías de lealtad hacia quienes detentan el monopolio de la organización. Estas manifestaciones se acentúan cuando los partidos ignoran la desigual competencia que llevan hombres y mujeres, y se resisten a incluir incentivos que equilibren la balanza, tales como mayores recursos destinados a la formación política o al entrenamiento para el desarrollo de liderazgos.

No obstante, cuando se examinan los diferentes y variados logros acumulados en

2 Sobre un total de 24 distritos electorales, Argentina cuenta actualmente con tres gobernadoras: Fabiana Ríos en Tierra del Fuego (2007, reelecta en 2011); Lucía Corpacci en Catamarca (2011) y Claudia Ledesma Abdala en Santiago del Estero (2013). 
estos casi veinticinco ańos de cuotas legales en la región se distingue el fuerte impacto que tuvo al aumentar drásticamente el número de legisladoras y su correlato en una agenda parlamentaria más receptiva a las cuestiones de género.

Sin la acción continua de estas medidas, estos importantes adelantos no se hubieran alcanzado en tan poco tiempo.

\section{LAS CUOTAS DE GÉNERO EN AMÉRICA LATINA. LA PARIDAD COMO META}

La Ley 24.012, aprobada en Argentina en 1991, fue la primera norma en el mundo establecida para aumentar la representación de las mujeres en el ámbito parlamentario nacional.

Esta iniciativa fue posteriormente imitada por otros países latinoamericanos como México (1996), Paraguay (1996), Bolivia (1997), Brasil (1997), Costa Rica (1997), Ecuador (1997), Panamá (1997), Perú (1997), República Dominicana (1997), Venezuela (1997), Colombia (2000), Honduras (2000), Uruguay (2009), Haití (2011/2012) y El Salvador (2013) (tabla 1). De todos estos países, Colombia tuvo problemas para incorporarla en el ámbito parlamentario declarándose en inconstitucional algunos aspectos y retrasando así su aplicación. En Venezuela, por su parte, la Ley Orgánica del Sufragio y Participación Política de 1997 (LOSPP) consagró una cuota del $30 \%$ para mujeres en las listas de elección popular nacional, estadual, municipal y parroquial. No era aplicable para los cargos uninominales y tenía como sanción la no oficialización de las listas que no cumplieran con estos requisitos. Solo se aplicó una vez en 1998 y, dos años después, el Consejo Nacional Electoral (CNE) de la República Bolivariana de Venezuela consideró inconstitucional este artículo por violatorio del artículo 21 de la Constitución de $1999^{3}$.

Archenti y Tula $(2008,2010)$ han seńalado tres mecanismos institucionales que deben ser considerados en conjunto para la evaluación del impacto de las cuotas: i) al interior de los partidos políticos donde se diseñan los procedimientos de selección de candidaturas (proceso interno) y en donde se establece una configuración de género para el armado de la lista; ii) en las propias características distintivas de las leyes de cuotas (si incluyen su reconocimiento como de orden público, si son obligatorias para todos los partidos políticos o solo se limitan a exhortar su cumplimiento, si poseen algún mandato de posición y si tienen sanciones para quienes no la aplican), y iii) el sistema electoral, más favorable con magnitudes de distrito grandes y listas partidistas cerradas y bloqueadas (Norris, 1985; Rule, 1987; Caul, 1999; Htun y Jones, 2002), pero — siempre y cuando- las leyes de cuotas incluyan un mandato de posición.

3 El CNE fundamentó anular las cuotas de género porque creaban una ventaja inadmisible para las mujeres frente a los hombres. Sin embargo, en el apartado 2 del artículo 21 se garantizan las medidas de acción positiva tendientes a generar condiciones jurídicas y administrativas para que la igualdad sea real y efectiva ante la ley (García Prince, 2012; Madriz Sotillo, 2012). 
TABLA 1. PAÍSES CON CUOTAS LEGALES DE GÉNERO O PARIDAD EN AMÉRICA LATINA. CÁMARA BAJA O ÚNICA

\begin{tabular}{|c|c|c|c|c|c|c|}
\hline País & $\begin{array}{c}\text { Año } \\
\text { adopción }\end{array}$ & MD & EBV & $\begin{array}{c}\text { Cuota } \\
\text { mínima (\%) }\end{array}$ & Mandato de posición & $\begin{array}{l}\text { Sanción por in- } \\
\text { cumplimiento }\end{array}$ \\
\hline Argentina & 1991 & $\begin{array}{l}\text { Plurinominales } \\
\text { variables. Mínimo } \\
\text { 2-3 y máximo } 35\end{array}$ & $\begin{array}{l}\text { Cerrada y } \\
\text { bloqueada }\end{array}$ & 30 & $\begin{array}{l}\text { Sí ( } 1 \text { mujer cada } 3 \\
\text { candidatos) }\end{array}$ & Sí \\
\hline \multirow{2}{*}{$\begin{array}{l}\text { Estado Plu- } \\
\text { rinacional } \\
\text { de Bolivia }\end{array}$} & 1997 & \multirow{2}{*}{$\begin{array}{l}\text { Uninominales y } \\
\text { plurinominales } \\
\text { variables }\end{array}$} & \multirow{2}{*}{$\begin{array}{l}\text { Cerrada y } \\
\text { bloqueada }\end{array}$} & 30 & $\begin{array}{l}\text { Sí ( } 1 \text { mujer cada } 3 \\
\text { candidatos) }\end{array}$ & Sí \\
\hline & 2009 & & & Paridad 50 & $\begin{array}{l}\text { Sí (alternancia secuen- } \\
\text { cial en ambos sexos) }\end{array}$ & Sí \\
\hline Brasil & 1997 & $\begin{array}{l}\text { Plurinominales } \\
\text { variables. Mínimo } \\
8 \text { y máximo } 70\end{array}$ & $\begin{array}{l}\text { Cerrada y } \\
\text { desbloqueada }\end{array}$ & $\begin{array}{l}30 \text { (a partir } \\
\text { de 2002) }\end{array}$ & No & Sí \\
\hline Colombia & 2011 & $\begin{array}{l}\text { Plurinominales } \\
\text { variables. Mínimo } \\
2 \text { y máximo } 18\end{array}$ & $\begin{array}{l}\text { Opcional: } \\
\text { cerrada y } \\
\text { bloqueado/ } \\
\text { Cerrada y } \\
\text { desbloqueada }\end{array}$ & 30 & No & Sí \\
\hline \multirow[b]{2}{*}{ Costa Rica } & 1996 & \multirow{2}{*}{$\begin{array}{l}\text { Plurinominales } \\
\text { variables. Mínimo } \\
4 \text { y máximo } 19\end{array}$} & \multirow{2}{*}{$\begin{array}{l}\text { Cerrada y } \\
\text { bloqueada }\end{array}$} & 40 & Sí & Sí \\
\hline & 2009 & & & 50 & $\begin{array}{l}\text { Sí (alternancia secuen- } \\
\text { cial en ambos sexos) }\end{array}$ & Sí \\
\hline \multirow{4}{*}{ Ecuador } & 1997 & \multirow{4}{*}{$\begin{array}{l}\text { Plurinominales } \\
\text { variables. Mínimo } \\
2 \text { y máximo } 15\end{array}$} & \multirow{4}{*}{ Abierta } & 20 & Sí & Sí \\
\hline & 2000 & & & $\begin{array}{l}30 \\
\text { (progresivo } \\
\text { hasta } \\
\text { paridad) }\end{array}$ & Sí & Sí \\
\hline & 2006 & & & 45 & Sí & Sí \\
\hline & $\begin{array}{l}2008 y \\
2009\end{array}$ & & & Paridad 50 & $\begin{array}{l}\text { Sí (alternancia secuen- } \\
\text { cial en ambos sexos) }\end{array}$ & Sí \\
\hline El Salvador & 2013 & $\begin{array}{l}\text { Plurinominales } \\
\text { variables }\end{array}$ & $\begin{array}{l}\text { Lista cerrada y } \\
\text { desbloqueada }\end{array}$ & 30 & No & Sí \\
\hline Haití & $\begin{array}{l}2011- \\
2012\end{array}$ & $\begin{array}{l}\text { Uninominales con } \\
\text { ballotage }\end{array}$ & $\begin{array}{l}\text { Cerrada y } \\
\text { bloqueada }\end{array}$ & 30 & No & No \\
\hline \multirow[b]{2}{*}{ Honduras } & 2000 & \multirow[b]{2}{*}{$\begin{array}{l}\text { Plurinominales } \\
\text { variables. Mínimo } \\
1 \text { y máximo } 23\end{array}$} & \multirow[b]{2}{*}{$\begin{array}{l}\text { Cerrada y } \\
\text { bloqueada }\end{array}$} & 30 & No & Sí \\
\hline & 2012 & & & $\begin{array}{l}40 \\
\text { (progresivo } \\
\text { hasta } \\
\text { paridad) }\end{array}$ & No & No \\
\hline
\end{tabular}




\begin{tabular}{|c|c|c|c|c|c|c|}
\hline País & $\begin{array}{c}\text { Año } \\
\text { adopción }\end{array}$ & MD & EBV & $\begin{array}{c}\text { Cuota } \\
\text { mínima (\%) }\end{array}$ & Mandato de posición & $\begin{array}{l}\text { Sanción por in- } \\
\text { cumplimiento }\end{array}$ \\
\hline \multirow{3}{*}{ México } & 1996 & \multirow{3}{*}{$\begin{array}{l}\text { Uninominales y } \\
\text { plurinominales }\end{array}$} & \multirow{3}{*}{$\begin{array}{l}\text { Cerrada y } \\
\text { bloqueada }\end{array}$} & 30 & Síc & Sí \\
\hline & 2008 & & & 40 & $\begin{array}{l}\text { Sí. En cada segmento } \\
\text { de } 5 \text { candidaturas, } \\
2 \text { tienen que ser de } \\
\text { género distinto }\end{array}$ & Sí \\
\hline & 2014 & & & Paridad 50 & Sí & Sí \\
\hline \multirow{2}{*}{ Panamá } & 1997 & \multirow{2}{*}{$\begin{array}{l}\text { Plurinominales } \\
\text { variables. Mínimo } \\
2 \text { y máximo } 7\end{array}$} & \multirow{2}{*}{$\begin{array}{l}\text { Cerrada y } \\
\text { desbloqueada }\end{array}$} & 30 & No & No \\
\hline & 2012 & & & Paridad 50 & No & No \\
\hline Paraguay & 1996 & $\begin{array}{l}\text { Plurinominales } \\
\text { variables. Mínimo } \\
1 \text { y Máximo } 19\end{array}$ & $\begin{array}{l}\text { Cerrada y } \\
\text { bloqueada }\end{array}$ & 20 & $\begin{array}{l}\text { Sí ( } 1 \text { mujer cada } 5 \\
\text { candidatos) }\end{array}$ & Sí \\
\hline \multirow{2}{*}{ Perú } & 1997 & \multirow{2}{*}{$\begin{array}{l}\text { Plurinominales } \\
\text { variables. Mínimo } \\
1 \text { y máximo } 35\end{array}$} & \multirow{2}{*}{$\begin{array}{l}\text { Cerrada y } \\
\text { desbloqueada }\end{array}$} & 25 & No & Sí \\
\hline & 2000 & & & 30 & Sí & Sí \\
\hline \multirow{2}{*}{$\begin{array}{l}\text { República } \\
\text { Domini- } \\
\text { cana }\end{array}$} & 1997 & \multirow{2}{*}{$\begin{array}{l}\text { Plurinominales } \\
\text { variables. Mínimo } \\
2 \text { y máximo } 44\end{array}$} & \multirow{2}{*}{$\begin{array}{l}\text { Cerrada y } \\
\text { bloqueada } \\
\text { (desde 2010) }\end{array}$} & 25 & No & No \\
\hline & 2002 & & & 33 & Sí & Sí \\
\hline Uruguay & 2009 & $\begin{array}{l}\text { Plurinominales } \\
\text { variables. Mínimo } \\
2 \text { y máximo } 43\end{array}$ & $\begin{array}{l}\text { Cerrada y } \\
\text { bloqueada }\end{array}$ & 33 & $\begin{array}{l}\text { Sí (incluir personas } \\
\text { de ambos sexos } \\
\text { en cada terna de } \\
\text { candidatos) }\end{array}$ & Sí \\
\hline
\end{tabular}

Fuente: elaboración propia con base en datos de Observatorio de Igualdad de Género de América Latina y el Caribe, CEPAL//www.cepal.org/oig/\#, Archenti y Tula (2008), www.quotaproject.org y сІм (2010).

Sigla: MD: Magnitud de Distrito; EBv: Estructura de la Boleta de Votación. Nota: 1) En Brasil un partido político puede presentarse a elecciones si cumple con el máximo del $70 \%$ candidatos de un mismo sexo pero no es necesario que incorpore el $30 \%$ restante con candidatos del otro sexo (Marx, Borner y Caminotti, 2007, p. 303). 2). En Panamá, la paridad aplica para las elecciones primarias o internas de los partidos pero no a la lista que se presenta en elecciones generales.

La combinación de estos tres dispositivos condiciona la aplicación efectiva de las cuotas al determinar contextos favorables o desfavorables en cada distrito para que las mujeres sean finalmente electas. También para garantizar un crecimiento continuo en el tiempo y no tan dependiente de otras variables intervinientes en la contienda electoral, como el posicionamiento de los adversarios, los apoyos políticos internos, la ausencia de recursos para solventar los gastos de campańas electorales (más aún si los países cuentan con listas abiertas o cerradas y desbloqueadas), y el acceso a los medios masivos de comunicación. Por tanto, el impacto de esta medida solo puede ser tomado observando el conjunto y no de manera aislada (Archenti y Tula, 2008; Krook, 2006; Norris y Lovenduski, 1993). 
TABLA 2. MUJERES EN LOS PARLAMENTOS DE AMÉRICA LATINA. PAÍSES CON LEYES DE CUOTAS O PARIDAD. CÁMARA BAJA O ÚNICA

\begin{tabular}{|c|c|c|c|c|c|}
\hline País & $\begin{array}{c}\% \text { de mujeres } \\
\text { sobre total } \\
\text { escaños previo a } \\
\text { las cuotas/ Año }\end{array}$ & Última elección & Mujeres & $\begin{array}{l}\text { \% mujeres sobre } \\
\text { total escaños/ } \\
\text { Última elección }\end{array}$ & $\begin{array}{l}\text { Posición en el } \\
\text { mundo según } \\
\text { escaños } 2014\end{array}$ \\
\hline Ecuador & No hay datos & Febrero 2013 & 57 & 41,6 & 9 \\
\hline México & $14,2(1994)$ & Julio 2012 & 187 & 37,4 & 18 \\
\hline Argentina & 8,7 (1989) & Octubre 2013 & 94 & 36,6 & 20 \\
\hline Costa Rica & $15,8(1994)$ & Febrero 2014 & 19 & 33,3 & 27 \\
\hline El Salvador & No aplica & Marzo 2012 & 23 & 27,4 & 42 \\
\hline Honduras & 9,4 (1997) & Noviembre 2013 & 33 & 25,8 & 50 \\
\hline Bolivia & 6,9 (1993) & Diciembre 2009 & 33 & 25,4 & 52 \\
\hline Perú & 10,8 (1995) & Abril 2011 & 29 & 22,3 & 67 \\
\hline $\begin{array}{l}\text { República } \\
\text { Dominicana }\end{array}$ & 11,7 (1994) & Octubre 2010 & 38 & 20,8 & 72 \\
\hline Colombia & $12,7(2010)$ & Marzo 2014 & 33 & 19,9 & 76 \\
\hline Panamá & 9,7 (1994) & Mayo 2014 & 11 & 19,3 & 79 \\
\hline Venezuela & $5,9(1993)$ & Octubre 2010 & 28 & 17 & 89 \\
\hline Paraguay & 2,5 (1993) & Abril 2013 & 12 & 15 & 98 \\
\hline Uruguay & No aplica & Octubre 2010 & 13 & 13,1 & 109 \\
\hline Brasil & $6,6(1994)$ & Octubre 2010 & 44 & 8,6 & 131 \\
\hline Haití & $4,1(2006)$ & Noviembre 2010 & 4 & 4,2 & 143 \\
\hline
\end{tabular}

Fuente: elaboración propia a partir de diferentes fuentes: http://www.ipu.org/wmn-e/arc/classif010914.htm y Krook (2008). Nota: se consideran solo los países que tienen normativa de cuota de género o paridad aunque algunos de ellos todavía no las hayan aplicado, como son los casos de Uruguay y El Salvador.

Una rápida mirada a la tabla 2 confirma lo dicho. La heterogeneidad de los efectos de la aplicación de las cuotas se explica a partir de cómo cada uno de los países que sancionaron acciones afirmativas lo hicieron con un diseño normativo favorable (piso mínimo del $30 \%$, mandato de posición posprimarias, sanción de no oficialización de la lista para quienes incumplen). Allí están Ecuador encabezando la tabla de posiciones (desde 2009 tiene paridad) y Brasil — la democracia más grande del continente- casi al final con un 8,6\%, con una legislación débil y un sistema electoral desfavorable (voto preferencial) ${ }^{4}$.

4 Si bien Ecuador cuenta con un sistema electoral de lista abierta, puede mantener el porcentaje de representación 
Si bien estos impactos han sido desiguales en términos cuantitativos, han resultado herramientas exitosas desde el punto de vista cualitativo. Una mayor presencia de mujeres en las listas electorales amplió los márgenes de acción en otras esferas del ámbito público tradicionalmente consideradas masculinas. También se han ido incorporando al debate nuevas temáticas vinculadas a los derechos de las mujeres anteriormente invisibilizados tanto en la agenda parlamentaria como pública.

Como se observa en la tabla 2, la participación política de las mujeres ha tenido un gran avance en la región desde que se aplicaron las cuotas legales por primera vez en cada país. Pero, desde entonces, se advierte con preocupación un efecto meseta en este crecimiento, aun en los países que gozan de escenarios favorables. La respuesta a esta situación debe buscarse al interior de los partidos políticos, más precisamente en los procesos internos de selección de candidatos.

En efecto, el cambio de reglas en el armado de las listas, que incluían más mujeres, fue percibido como una amenaza y no como una medida tendiente a generar espacios más equitativos entre hombres y mujeres. Las reiteradas y conocidas maniobras efectuadas por los partidos políticos, tales como ubicar a las candidatas en lugares poco atractivos, obligarlas a renunciar antes de asumir su mandato para que acceda un hombre, entre otras, continúan siendo moneda corriente. La práctica más difundida ha sido la interpretación "burócrática y minimalista" (Archenti y Tula, 2010), es decir, el cumplimiento numérico a rajatabla de lo que estipula la ley. Pocas veces las mujeres superan el porcentaje mínimo exigido por la cuota, lo que en la práctica convierte este piso legal en un techo máximo.

Los diversos obstáculos que, en diferentes contextos políticos, afectaron la efectividad de las leyes de cuotas, han abierto el debate sobre la paridad política de género. Esta es entendida como una medida definitiva (y no ya transitoria ni correctiva como sucede con las cuotas de género) que busca extender el derecho a la igualdad a través de la inclusión de un $50 \%$ de candidaturas de cada género en forma secuencial y alternada (uno a uno).

Tres países de la región ya aplicaron la paridad electoral en elecciones generales: Bolivia, Ecuador y Costa Rica. Por su parte, México sancionó una ley paritaria en diciembre de 2013 y Honduras — de continuar la proyección progresiva - hará elecciones paritarias en 2016. Si bien sus impactos han sido heterogéneos a nivel cuantitativo, las leyes de paridad permiten superar muchas dificultades que presentan las leyes de cuotas a la hora de aplicarse. Se constituyen así, no solo como un objetivo de igualdad de género fundado en la igualdad de derechos, sino también como una medida pragmática que resuelve: 1) la

más alto debido a que en los dos últimos comicios (2009 y 2013) los partidos políticos tomaron como estrategia votar por la lista de partido completa o plancha. Solo de esta manera es posible comprender el mantenimiento de una configuración de género paritaria respetando el mandato de posición de alternancia y secuencialidad entre sexos. Para más detalles ver Archenti y Tula (2014). 
ausencia de un mandato de posición y 2) la consideración del porcentaje mínimo de las cuotas como un techo máximo (Archenti y Tula, 2014).

\section{MUJERES Y POLÍTICA EN COLOMBIA}

Como en otros países de América Latina, el reconocimiento del derecho al voto de las mujeres colombianas en la reforma constitucional de 1954 no significó el pasaje hacia una participación equitativa de géneros en los procesos políticos de decisión. Desde entonces, y hasta mediados de los años setenta, han sido muy pocas las mujeres que ocuparon cargos en organismos colegiados como el Congreso, las asambleas departamentales o los concejos municipales. Por estos años, el promedio de participación política de las mujeres fue de 2,01 \% para el Senado, 4,43\% para la Cámara de Representantes, $8,15 \%$ en las asambleas departamentales y 6,69\% en los concejos municipales (Córdoba Ruiz, 2002).

Recién en 1991, la modificación de la Constitución Nacional reconoció la igualdad entre hombres y mujeres en los artículos 13 y 43. Junto a esta incorporación, el artículo 40 obligaba a garantizar la adecuada y efectiva participación de las mujeres en los niveles de decisión de la administración pública. En síntesis, este nuevo marco regulatorio amplió los espacios de participación política, reconoció la diversidad étnica y multicultural de la nación colombiana, introdujo la noción de igualdad entre los individuos y la definición de una serie de derechos sobre la base de los principios liberales de igualdad, justicia, libertad y paz. La introducción de estos puntos constituyó un quiebre frente al régimen que prevaleció hasta 1991 bajo la Constitución Política de 1886 (León y Holguín, 2005).

Sin embargo, la persistencia de ciertos patrones culturales patriarcales, junto a una distribución desigual del poder político, no solo mostraron que este marco legal era insuficiente e ineficiente, sino que también era necesario tomar medidas específicas para garantizar la igualdad en términos de género.

Entre 1991 y 2011, Cardozo García y Quintero Benavides (2014) identifican dos etapas en las acciones legislativas tendientes a superar la baja representación de las mujeres en los órganos políticos de decisión.

La primera de ellas, entre 1991 y 2000, cuando un pequeńo grupo de seis iniciativas se sometió a debate y una de ellas se aprobó. Este fue el caso de la Ley Estatutaria 581 de 2000, conocida también como la primera Ley de Cuotas, cuya sanción fue el primer paso hacia la ampliación de garantías para la participación política de las mujeres. Esta norma señala que el $30 \%$ de los cargos de máximo nivel decisorio y otros niveles en la estructura de la administración pública, deben ser ocupados por las mujeres, garantizándoles la adecuada y efectiva participación en todos los niveles de las ramas y demás órganos del poder público.

Sin embargo, la revisión por la Corte Constitucional originó un traspié cuando en la sentencia C-321/00 estableció que su influencia en el campo electoral no era posible dado que violaba los artículos 40, 107, 108 y 109 de la Constitución Nacional que garantizaban la libertad de asociación y organización interna de los partidos. En efecto, la Constitución 
Política de 1991 establecía que los partidos políticos son autónomos, que los ciudadanos pueden constituirlos sin limitación alguna y, sobre todo, que el Estado en ningún caso podrá establecer exigencias en relación con la organización interna de los partidos y los movimientos políticos. Así, el ámbito de ejecución de esta ley se centró en los cargos de decisión dentro de la administración pública y no en la conformación de las candidaturas al interior de los partidos políticos.

El segundo impulso se dio entre 2001 y 2011 cuando se sucedieron tres modificaciones constitucionales producto de las reformas políticas de 2003, 2009 y 2011 que fueron modelando el sistema político vigente. Los aspectos centrales de la reforma de 2003 se orientaron a fortalecer internamente a los partidos políticos y reducir la fragmentación del sistema de partidos. Así, la obligación de presentar una única lista (con opción de elegir entre listas cerradas o con voto preferente), como la inclusión de pisos o umbrales para la elección de senadores, el mantenimiento de la personería jurídica y la distribución de escaños en distritos plurinominales, junto con la modificación de la fórmula electoral, la prohibición de la doble militancia y la creación de un régimen de bancadas tuvieron su impacto en los comicios de 2006 donde demostraron la efectividad de la puesta en marcha de estas medidas (Puyana, 2012).

Por su parte, la reforma de 2009 abordó con especial atención, aunque no exclusivamente, el funcionamiento interno de los partidos. Siguiendo a Puyana (2012), cuatro fueron los temas relevantes de esta reforma: i) el régimen sancionatorio para organizaciones políticas que avalen candidatos con vínculos con fuerzas ilegales, dentro del cual la silla vacía es el principal exponente; ii) aspectos relacionados con el sistema electoral como el incremento del umbral y las limitaciones a la doble militancia; iii) la democratización interna de los partidos y movimientos políticos junto con la equidad de género, y iv) medidas sobre el financiamiento de la política.

Tanto Puyana (2012) como Ortega y Camargo (2012) coinciden en señalar que estas modificaciones fueron el punto de partida para debatir la actualización de la ley de partidos políticos (hasta entonces vigente en la Ley 130 de 1994) y reanudar el tratamiento de otorgar mayores garantías constitucionales de igualdad y equidad de género en los cargos públicos electivos de representación popular.

Hacia mediados de 2010, el Gobierno nacional presentó el proyecto de ley estatutaria que dio lugar a la Ley 1475 de 2011, que introdujo la cuota de género en las listas electorales. Con 55 artículos en total, esta norma profundizó sobre: 1) los principios $y$ el funcionamiento interno de partidos y movimientos políticos; 2) el régimen de responsabilidad de dichas organizaciones $y$, en especial, de sus directivas; 3 ) la financiación de partidos y movimientos, por un lado, y de las campañas electorales, por el otro, y 4) el funcionamiento del sistema electoral.

\section{La Ley 1475 de 2011. Una oportunidad para el cambio}

Si bien la Ley 1475 es una norma por la cual se adoptan reglas generales en la organización y el funcionamiento de los partidos y 
movimientos políticos, así como en los procesos electorales, en su artículo 28 incorpora las cuotas de género para elecciones representativas. Después de once años desde que se sancionara la Ley 581, esta legislación representa un importante avance en el reconocimiento de las mujeres y su derecho a ser elegidas.

Interesa destacar que, ya en el primer artículo, se incluyen principios rectores sobre los cuales los partidos y movimientos políticos deben garantizarlos en sus propios estatutos. Estos son los de transparencia, objetividad, moralidad, equidad de género y el deber de presentar y divulgar sus programas políticos de conformidad con lo dispuesto en la legislación existente. Pero además, define los contenidos mínimos de los siguientes seis conceptos: participación, igualdad, pluralismo, equidad e igualdad de género y moralidad a los fines de homogeneizar la interpretación que cada partido y movimiento político adopte de ella. En esta dirección, el punto 4, titulado Equidad e igualdad de género, establece que "en virtud del principio de equidad e igualdad de género, los hombres, las mujeres y las demás opciones sexuales gozarán de igualdad real de derechos y oportunidades para participar en las actividades políticas, dirigir las organizaciones partidistas, acceder a los debates electorales y obtener representación política”.

Más concretamente, en el Título III referido a las campañas electorales, y en el Capítulo I, que versa sobre la inscripción de candidatos, el artículo 28 señala muy escuetamente que "las listas donde se elijan cinco o más curules para corporaciones de elección popular o las que se sometan a consulta - exceptuando su resultado- deberán conformarse por mínimo un $30 \%$ de uno de los géneros". La sanción frente a su incumplimiento es la no oficialización de las listas que participarán de la contienda electoral.

En la sentencia C-490 de 2011, la Corte se pronunció sobre la exequibilidad de esta norma, en particular la que se refiere al porcentaje mínimo del $30 \%$. El tribunal constitucional consideró que tal disposición se ajusta a la Constitución dado que:

... promueve la igualdad sustancial en la participación de las mujeres en la política, estableciendo una medida de carácter remedial, compensador, emancipatorio y corrector a favor de un grupo de personas ubicado en situación sistémica de discriminación; realiza los principios democráticos y de equidad de género que rigen la organización de los partidos y movimientos políticos, a la vez que desarrolla los mandatos internacionales y de la Constitución sobre el deber de las autoridades de garantizar la adecuada y efectiva participación de la mujer en los niveles decisorios de la administración pública. Se trata, además, de una medida que si bien puede limitar algunos de los contenidos de la autonomía de los partidos y movimientos políticos, persigue una finalidad importante, es adecuada y necesaria para alcanzar dicho fin, a la vez que resulta proporcional en sentido estricto.

Respecto de los aspectos más favorables considerados en la constitución de la ley de cuotas de género se observa que esta carece de un mandato de posición, esto es, no estableció una configuración de género para el ordenamiento de la lista en donde se intercalen los géneros en toda su extensión. Tal vez pensando que su inclusión resultaría innecesaria dado que los partidos y movimientos políticos pueden optar por el voto preferente $y$, en 
consecuencia, se habilita el reordenamiento vertical de las candidaturas según las votaciones alcanzadas individualmente por cada uno de ellos. Vale decir, que mientras los partidos y movimientos políticos cumplan con el mínimo del $30 \%$, todas las mujeres candidatas pueden ser incluidas en las últimas posiciones de la papeleta electoral.

El requisito del mandato de posición es importante no solo para las legislaciones de cuotas que se combinan con sistemas electorales de listas cerradas y bloqueadas porque obliga a ubicar a las mujeres en lugares espectables (es decir, con posibilidades reales de ser electas) sino también porque promociona y difunde una mayor visibilidad de las mujeres en los primeros lugares del tarjetón electoral. La posición que asuman hombres y mujeres no debe soslayarse dado que impacta sobre el valor que los partidos asignan al género subrepresentado.

Según el informe de Observación Electoral de la Organización de Estados Americano (OEA) sobre las últimas elecciones celebradas en marzo de 2014, la participación de las mujeres en cargos directivos en los partidos o movimientos políticos sigue siendo escasa y muy heterogénea. Solo 3 (25\%) de las agrupaciones poseen $50 \%$ o más de mujeres en sus juntas ejecutivas, mientras que, en el 58,3\% de los partidos políticos la participación de las mujeres en los cuerpos decisorios oscila entre el 10 y el $40 \%$ y 2 colectividades no incluyen a ninguna mujer (2014, p. 7).

Por esta razón, para el caso específico de Colombia, la introducción de un mandato de posición permitiría visibilizar, naturalizar y rutinizar la participación de las mujeres en política aun cuando el voto preferente no les asegure un escańo. Así, cuando un partido o movimiento político incorpora a las mujeres en las primeras posiciones de su lista está demostrando a la ciudadanía que promueve la real igualdad de derechos y oportunidades entre los géneros conforme al artículo 1, numeral 4 de la Ley 1475, y que no se trata de una estrategia discursiva poco efectiva.

De otro lado, la exclusión de la aplicación de la cuota de género en los distritos que eligen menos de cinco candidatos obliga a pensar que el mecanismo compensatorio de la cuota de género privilegia a las circunscripciones de mayor población. Vale decir que, el camino hacia la equidad de género incorporado en la Constitución Política no se cumple por igual y con el mismo rigor legal en todo el territorio del país. Así, las mujeres de los departamentos que eligen menos de cinco escaños no gozan de los mismos derechos que sus pares de distritos más poblados. Esta diferencia regional de género castiga aún más a las zonas deprimidas económicamente y que han sido afectadas, por ejemplo, por el conflicto armado.

Si bien la Ley 1475 introdujo otras medidas relacionadas con el financiamiento de los partidos para que estos promuevan, no solo la participación de las mujeres, sino también incrementen sus posibilidades reales de acceso en los órganos representativos, resulta una medida diseñada en función de los resultados y este beneficio se restringe solo a los partidos políticos que tuvieron representación parlamentaria. Es decir, la norma prevé un incentivo económico para; i) aquellos partidos con mayor número de mujeres electas en los cuerpos colegiados, y ii) para los grupos subre- 
presentados como mujeres, jóvenes y minorías étnicas; pero iii) no señala cómo deberían orientarse estos recursos durante la campaña electoral para que hombres y mujeres gocen de un trato igual sobre estos fondos, y iv) no resulta un incentivo para aquellos partidos y movimientos políticos que alentaron la participación de mujeres y no ganaron escaños.

En el estudio comparativo de Llanos (2014) sobre ocho países de América Latina, la autora seńala la inequidad de género en la cobertura de las candidaturas que los medios de comunicación efectúan. Según esta investigación, en las elecciones para la Cámara de Representantes de Colombia en 2011, los hombres tuvieron acceso en un $91,7 \%$ frente a un $18,3 \%$ de las mujeres mientras que para el Senado esta diferencia fue de 77 frente a $23 \%$, respectivamente. Cuando se centra la atención sobre el tipo de medio (prensa escrita, radio y televisión), la brecha se acentúa para el caso de las candidaturas a la Cámara de Representantes y su exposición en la televisión (4,9\% para las mujeres y 95,1\% para los hombres) mientras que para el Senado es de 15,8 y $84,2 \%$, respectivamente. El estudio también advierte sobre la vigencia de ciertos estereotipos de género en el imaginario periodístico al momento de presentar noticias relacionadas con las candidaturas o los liderazgos de mujeres, vinculados a roles domésticos, familiares y de la vida privada.
$\mathrm{Al}$ respecto - $-\mathrm{y}$ frente a la contundencia de estos datos-, la legislación electoral debiera contemplar un mecanismo de financiamiento dirigido a las candidaturas de las mujeres para enfrentar la campaña política más equitativamente (en particular quienes no han obtenido cargos previamente) con el fin de que estas logren posicionar su imagen frente a la sociedad. Y promover en los medios de comunicación la implementación de herramientas para el análisis político con perspectiva de género.

\section{Su interacción con el sistema electoral}

En todo sistema electoral es posible reconocer al menos cuatro elementos constitutivos: la magnitud del distrito, la fórmula electoral, la barrera legal y la estructura del tarjetón de votación (también conocida como tipo de lista). Según la manera en que se combinen estos atributos, los sistemas electorales impactarán de modo diferente en los órganos legislativos al definir una representación política de tipo mayoritaria o proporcional. Sin embargo, no todos estos elementos del sistema electoral inciden directamente en la aplicabilidad de las cuotas, solo la magnitud del distrito $(\mathrm{MD})$ y la estructura del tarjetón de votación (EBV) son los que tienen mayor peso a la hora de configurar escenarios favorables o desfavorables ${ }^{5}$. En el caso de Colombia, tanto

5 Se entiende por magnitud de distrito al número de bancas que se eligen en un determinado territorio. Este puede ser: nacional, provincial, departamental, municipal o seccional. Según su tamańo, se pueden clasificar en uninominales o plurinominales. Los primeros eligen un solo representante y en ellos solo es posible aplicar el principio de decisión por mayoría; en cambio, en los segundos se pueden elegir dos o más candidatos por circunscripción. Según 
la MD como la EBV adoptan una configuración adversa a las condiciones de acceso a la representación de las mujeres.

\section{La magnitud del distrito}

En efecto, Colombia cuenta con 32 departamentos y un distrito capital, vale decir, 33 distritos plurinominales de tamańo variable a los efectos de elegir los legisladores de la Cámara de Representantes, las asambleas departamentales, los concejos municipales y las juntas administrativas locales

Siguiendo a Nohlen (1994), los miembros de la Cámara de Representantes son electos en tres distritos grandes (Antioquia, Bogotá y Valle), seis medianos (Atlántico, Bolívar, Boyacá, Cundinamarca, Santander y Tolima) y 24 pequeños (todo el resto). La literatura especializada en este tema proporciona mucha información sobre la relación positiva que existe entre las magnitudes de distrito grande y la mayor posibilidad de acceso de mujeres en los órganos de representación (Norris, 1985; Jones, 2000; Peschard, 2004). Así, cuanto más grande sea la magnitud del distrito, mayor es la probabilidad de incluir candidatas mujeres en las listas partidistas en la medida que hay más escańos en juego y, en consecuencia, mayores posibilidades de que estas resulten electas. En contraposición, las circunscripciones pequeñas tienden a limitar la efectividad de las cuotas ya que los partidos políticos suelen obtener entre uno o dos escaños en una misma circunscripción. Así, como la mayoría de las veces los primeros lugares del tarjetón son ocupados por hombres, estos son los únicos que tienen posibilidades "reales" de acceder a los escańos.

Sin embargo, cabe destacar que en el resultado final por ganar el escańo también impactan otras variables tales como la fragmentación o concentración del sistema partidista (oferta electoral amplia o reducida) y la concentración o dispersión electoral (los votos de los ciudadanos se concentran en unos pocos partidos, o bien, se reparten entre varios proporcionalmente). Así, un escenario como el de las pasadas elecciones en Colombia, en marzo de 2014, con una oferta electoral importante y dispersa, los partidos políticos no pueden asegurarse más que un mínimo de escaños cada uno en cada circunscripción electoral. Si a esto se suma la carencia de un mandato de posición en la aplicación de las cuotas, el escenario es aún más perjudicial para las mujeres dado que generalmente son ubicadas en posiciones poco espectables. Por último, descartando los departamentos que eligen menos de cinco escaños porque la Ley 1475 los exceptúa, las cuotas de género se aplican en catorce departamentos, es decir, en menos de la mitad ${ }^{6}$.

Nohlen (1994), los distritos plurinominales se clasifican en pequeños (entre dos y cinco representantes), medianos (entre seis y diez) y grandes (más de diez).

6 Los 19 restantes son Amazonas, Arauca, Caquetá, Casanare, Cauca, César, Chocó, Guainía, Guaviare, Huila, La Guajira, Meta, Putumayo, Quindío, Risaralda, San Andrés, Sucre, Vaupés y Vichada, los cuales eligen entre 2, 3 y 4 bancas. 


\section{La estructura del tarjetón electoral}

La estructura del tarjetón electoral hace referencia a la existencia o no de diferentes posibilidades en manos del elector de expresar su preferencia entre diversos partidos políticos o postulantes, determinando, por tanto, la presencia de listas cerradas y bloqueadas, listas cerradas y desbloqueadas o listas abiertas ${ }^{7}$. Tanto la lista cerrada y desbloqueada como la lista abierta producen una competencia electoral que se desarrolla en dos planos: el externo (competencia interpartidista) que determina cuántos escańos obtiene cada partido político, y el interno (competencia intrapartidista) que define quiénes ocuparán los escaños ganados por cada agrupación.

La lista cerrada y bloqueada tiene un impacto positivo en la efectividad de las cuotas en tanto impide la alteración posterior del orden de los candidatos, evitando así que se anule —en caso de existir - el mandato de posición preestablecido por la ley de cuotas. Por el contrario, el uso del voto preferente rompe con los acuerdos o equilibrios que se intentan preservar en el ámbito político al habilitar la modificación del orden de las candidaturas previamente determinado por el partido político. También repercute negativamente en los sectores minoritarios la excesiva personalización de la campaña electoral (pro- ducto de la competencia intrapartidista), dado que requieren - para competir en igualdad de condiciones - de mayores recursos económicos y de apoyos políticos importantes.

Cuando un partido elige usar una lista cerrada y bloqueada, el peso de las cualidades individuales de cada candidato se va diluyendo o pierde importancia en la medida que aumenta la magnitud del distrito, así como el voto preferente aumenta el valor de la reputación personal cualquiera sea la magnitud del distrito sobre el que se compite (Carey y Shugart, 1995).

Como sostiene Katz (1986), todo voto preferencial intrapartidista promueve la personalización de la política introduciendo así otra cuestión relacionada con cómo se orientan los recursos en las organizaciones políticas a través del financiamiento partidista durante la campaña electoral. Y este escenario resulta más complejo para quienes no tienen algún tipo de padrinazgo político o recién se inician en la política, como ocurre con el universo de mujeres y sectores jóvenes. Por el contrario, resulta más accesible para quienes reeligen porque ya son conocidos, pueden mostrar capacidad de gestión de gobierno, tienen una relación más directa con los medios de comunicación y gozan de cierta influencia al interior del partido.

\footnotetext{
7 Se denomina "cerrada y bloqueada" cuando no hay posibilidades de modificar la boleta electoral y debe respetarse la decisión partidista en el proceso de selección de candidaturas como el orden adjudicado a estas. En cambio, cuando la lista es "cerrada y desbloqueada" se admite una movilidad de tipo "vertical" (o de reordenamiento intrapartido), al poder alterarse el orden de los integrantes de una misma boleta partidista. Por último, la "lista abierta" también autoriza a los ciudadanos a una movilidad de tipo "horizontal" (o de reagrupamiento interpartido) al permitir no solo modificar el orden, sino también incorporar candidatos de otros partidos políticos (Nohlen, 1994).
} 
En los comicios de marzo de 2014 un $70 \%$ de las listas inscritas optaron por el voto preferente tanto para la circunscripción nacional como para la especial indígena. Y el $58 \%$ lo hizo para las listas de la Cámara de Representantes (circunscripción especial indígena y especial afrodescendiente) y el $67 \%$ para el Parlamento Andino (oeA, 2014, p. 7).

Frente a estos datos, el escenario más favorable para el acceso de las mujeres a la representación es el que combina: i) distritos plurinominales grandes (si superan los 15 escaños, mejor), ii) listas cerradas y bloqueadas, iii) legislación de cuotas o paridad con mandato de posición, iv) legislación de financiamiento partidario que incluya recursos para los gastos de campańa electoral a fin de que sea efectiva su competencia por el cargo y v) eliminación de las reelecciones indefinidas ya que estas no permiten la renovación de las dirigencias político-partidistas.

\section{La puesta en marcha. Las elecciones municipales de 2011 y las nacionales de 2014}

Las cuotas de género se aplicaron por primera vez para cargos electivos populares plurinominales el 30 de octubre de 2011 cuando se efectuaron las elecciones para autoridades regionales y locales. De acuerdo con varios estudios empíricos efectuados sobre estos comicios (Ortega y Camargo, 2012; Cardozo y Quintero, 2014), se identifican varios cambios importantes respecto de una mayor presencia de mujeres candidatas en las listas partidistas, comparado con las elecciones anteriores de 2007. Así, mientras que en 2007, el 86,8\% de las listas no incluía un mínimo del 30\% de mujeres, en 2011 ese porcentaje se revirtió incluso superando este piso. En 2011, el 36,3\% de las listas tuvieron candidatas entre un 30 y 33,3\%, cumpliendo así con el requisito mínimo porcentual que exige la ley, y un $7 \%$ de las listas presentadas superó este umbral incorporando mujeres en un $50 \%$ o más.

En cuanto al acceso de las candidatas a los órganos de representación, estos comicios representan una oportunidad para analizar cómo operan las cuotas de género en todos los departamentos por igual, ya que ninguno de ellos elige menos de cinco curules. Sin embargo, los datos señalan las dificultades de esta ley al combinarse con el voto preferente, más decisivo que el tamaño de los distritos, ya que según la Constitución Nacional los legisladores de las asambleas departamentales se eligen en distritos con magnitudes grandes (todos superan los diez escaños, art. 299). Más heterogéneo para el caso de los concejos municipales, los cuales se integran como mínimo con siete bancas (art. 132 de la Constitución Nacional).

En esta dirección, la tabla 3 muestra que el $73 \%$ de los departamentos tiene un promedio de mujeres en sus órganos de representación que oscila entre el 10 y el 19,9\%, cayendo a $21 \%$ la franja de representación que oscila entre 20 y 29,9\%. Como puede observarse en la tabla 4, en las asambleas departamentales el porcentaje mayor también corresponde entre el 10 y 19,9\%. Sin embargo, un 33,3\% restante se reparte entre los 11 departamentos que lograron superar el $20 \%$ de mujeres legisladoras. Respecto a elecciones 
TABLA 3. ELECCIONES A CONCEJOS DISTRITALES Y MUNICIPALES. PERIODO 2012-2015

\begin{tabular}{|c|c|c|c|}
\hline $\begin{array}{c}\% \text { Mujeres } \\
\text { electas }\end{array}$ & Departamentos & $\mathrm{N}$ & $\begin{array}{c}\% \text { sobre total depar- } \\
\text { tamentos } 33=100\end{array}$ \\
\hline-10 & Santander & 1 & 3 \\
\hline $10-19,9$ & $\begin{array}{l}\text { Antioquia, Arauca, Boyacá, Caldas, Casanare, Cauca, Cesar, Chocó, Córdoba, } \\
\text { Cundinamarca, Guaviare, Huila, La Guajira, Magdalena, Nariño, Norte de San- } \\
\text { tander, Putumayo, Risaralda, San Andrés, Sucre, Tolima, Valle, Vaupés, Vichada }\end{array}$ & 24 & 73 \\
\hline $20-29,9$ & Amazonas, Atlántico, Bogotá DC, Bolívar, Caquetá, Meta, Quindío & 7 & 21 \\
\hline+30 & Guainía & 1 & 3 \\
\hline 40 y más & -- & 0 & 0 \\
\hline
\end{tabular}

Fuente: elaboración propia sobre los datos de Cardozo y Quintero (2014).

TABLA 4. ELECCIONES A ASAMBLEAS DEPARTAMENTALES. PERIODO 2012-2015

\begin{tabular}{|c|l|c|c|}
\hline $\begin{array}{c}\text { \% mujeres } \\
\text { electas }\end{array}$ & \multicolumn{1}{|c|}{ Departamentos } & $\begin{array}{c}\text { N sobre total depar- } \\
\text { tamentos } 33=100\end{array}$ \\
\hline 0 & Boyacá, Risaralda & 2 & 6 \\
\hline-10 & Antioquia, Arauca, Caldas, Cauca, Guaviare, Nariño, Santander & 7 & 21,2 \\
\hline $10-19,9$ & $\begin{array}{l}\text { Caquetá, Cesar, Chocó, Córdoba, Cundinamarca, Magdalena, Meta, San Andrés, } \\
\text { Norte de Santander, Sucre, Tolima, Valle, Vichada }\end{array}$ & 13 & 39,4 \\
\hline $20-29,9$ & Bolívar, Bogotá DC, Casanare, Guainía, La Guajira, Vaupés & 6 & 18,2 \\
\hline+30 & Amazonas, Atlántico, Huila, Quindío & 4 & 12,1 \\
\hline 40 y más & Putumayo & 1 & 3 \\
\hline
\end{tabular}

Fuente: elaboración propia sobre los datos de Cardozo y Quintero (2014).

anteriores, el promedio de $17,9 \%$ de mujeres electas alcanzado en 2011 muestra que no hubo un incremento significativo respecto a $2007(17,2 \%)$ y $2003(16,8 \%)$.

El 9 de marzo de 2014, se aplicaron las cuotas de género por segunda vez pero, en esta ocasión, para cargos nacionales. Según el informe de Observación Electoral de la OEA, la participación política de las mujeres en el Congreso posaplicación de la cuota ha seguido una tendencia similar a su participación en corporaciones regionales: el aumento de mujeres en el registro de listas de candidatos es mayor al aumento en el porcentaje de mujeres electas. En esta ocasión, el número de candidatas inscritas en las listas electorales aumentó a 758 (33\%) de un total de 2408 candidatos. Respecto al total de mujeres electas para el período 2014-2018, este también aumentó de 37 (14\%) en 2010 a 52 (19,4\%) en 2014.

La tabla 5 muestra la evolución de las mujeres en la Cámara de Representantes y se observa que, respecto de ańos anteriores, la 
TABLA 5. CONGRESO DE LA REPÚBLICA DE COLOMBIA, CÁMARA DE REPRESENTANTES. PORCENTAJE DE MUJERES

\begin{tabular}{|c|c|c|c|c|c|c|c|c|c|}
\hline & \multicolumn{9}{|c|}{ Años } \\
\cline { 2 - 11 } & 1990 & 1997 & 1998 & 1999 & $\mathbf{2 0 0 0}$ & $\mathbf{2 0 0 1}$ & $\mathbf{2 0 0 2}$ & $\mathbf{2 0 0 3}$ & $\mathbf{2 0 0 4}$ \\
\hline$\%$ & 4,5 & 11,7 & -- & 11,8 & 11,8 & 11,8 & 12,0 & 12,0 & 12,0 \\
\hline
\end{tabular}

Fuente: Cepal, Cepalstat.

\begin{tabular}{|c|c|c|c|c|c|c|c|c|c|c|}
\hline & \multicolumn{10}{|c|}{ Años } \\
\cline { 2 - 13 } & 2005 & 2006 & 2007 & 2008 & 2009 & $\mathbf{2 0 1 0}$ & $\mathbf{2 0 1 1}$ & $\mathbf{2 0 1 2}$ & $\mathbf{2 0 1 3}$ & $\mathbf{2 0 1 4}$ \\
\hline$\%$ & 12,1 & 8,4 & 8,4 & 8,4 & 8,4 & 12,7 & 12,1 & 12,1 & 12,1 & 19,9 \\
\hline
\end{tabular}

Fuente: Cepal, Cepalstat.

TABLA 6. CONGRESO DE LA REPÚBLICA DE COLOMBIA, SENADO. PORCENTAJE DE MUJERES

\begin{tabular}{|c|c|c|c|c|c|c|c|}
\hline & \multicolumn{7}{|c|}{ Años } \\
\cline { 2 - 9 } & $1991-1994$ & $1994-1998$ & $1998-2002$ & $2002-2006$ & $\mathbf{2 0 0 6 - 2 0 1 0}$ & $\mathbf{2 0 1 0 - 2 0 1 4}$ & $\mathbf{2 0 1 4 - 2 0 1 8}$ \\
\hline$\%$ & 7,29 & 6,48 & 13,43 & 9,8 & 11,8 & 15,7 & 22,5 \\
\hline
\end{tabular}

Fuente: Córdoba (2002) e IPU (Inter-Parliamentary Union), Women in National Parliaments.

aplicación de la Ley 1475 ha sido significativa proporcionando un aumento cuantitativo de $+7,8 \%$ y rompiendo el piso aproximado de $12 \%$ que se venía sosteniendo de manera infrecuente desde 2000. Lo mismo ocurre cuando se observa la tabla 4 y la evolución que las senadoras han tenido de manera sostenida desde 2006, con un impacto mayor en 2014 de $+6,8 \%$.

Sin dudas, la aprobación de esta ley resulta un incentivo para promocionar la participación de las mujeres en Colombia, pero su efectividad mayor podrá encontrarse si existe voluntad política para perfeccionarla. Y, por supuesto, para impulsar acciones directas que busquen potenciar la equidad entre géneros.

\section{RECOMENDACIONES}

Por todo lo expuesto en este trabajo, en esta sección se brindarán dos propuestas de reforma política-electoral y una serie de recomendaciones generales con el fin de fortalecer los logros adquiridos en la participación política de las mujeres y mejorar las condiciones para un real acceso a la representación.

Propuesta 1. La aplicación de la paridad política como solución a los inconvenientes originados en las cuotas de género $(50 \%$ de mujeres y $50 \%$ de hombres en las listas).

Esta propuesta alternativa se orienta a superar los obstáculos derivados de la no aplicación de la cuota del $30 \%$ en todos los 
departamentos de Colombia por igual. En efecto, la actual legislación electoral 1475 de 2011 excluye a los departamentos que eligen menos de cinco escaños y, en consecuencia, las mujeres de estos distritos, generalmente los menos poblados, no gozan de los mismos derechos de elegir y ser elegidas que las colegas residentes en los departamentos más poblados. Se incurre así en una doble discriminación: territorial y por género. Con la inclusión de una configuración paritaria en la lista, alternada y secuencial (uno a uno), los 34 departamentos podrían cumplir con este requisito de ubicación de hombres y mujeres por igual.

Por otra parte, y con base en la experiencia de otros países latinoamericanos que ya llevan varios años aplicando las cuotas de género, se evitaría el "efecto meseta" como consecuencia de una actitud mezquina que tienen los partidos políticos de interpretar como un máximo lo que la legislación determinó como piso mínimo del $30 \%$.

Por último, la incorporación de la paridad política podría llevarse a cabo de manera gradual y progresiva emulando los antecedentes de Costa Rica, Ecuador y Honduras. La posibilidad de avanzar en este camino hacia la equidad de género en las listas de manera paulatina favorece la adaptación de los partidos políticos y sus estrategias frente al cambio. El propósito de una meta paritaria podría estar entre los objetivos de una nueva reforma política que busque aumentar escalonadamente el piso mínimo del $30 \%$.

Propuesta 2. De mantenerse la vigencia del Acto Legislativo 01 de 2003, por el cual se admite a los partidos optar por listas cerradas y bloqueadas o voto preferente, la aplicación de la legislación de las cuotas debería direccionarse de la siguiente manera: a) aplicación del mínimo del $30 \%$ de cuotas de género con mandato de posición para los partidos que opten por ir a las elecciones generales con listas cerradas y bloqueadas, b) aplicación de una configuración paritaria, alternada y secuencial, para los partidos y movimientos políticos que elijan ir con voto preferente.

Se equilibraría así el posicionamiento de los candidatos y las candidatas en las listas junto con sus expectativas de acceso a la representación.

1. En cuanto al financiamiento partidista, se han descrito las dificultades existentes en el escenario político actual para que tanto las mujeres como los sectores más jóvenes puedan efectuar campañas electorales en igualdad de condiciones. El acceso a los recursos económicos juega un papel importante en las condiciones de factibilidad, más aun, si los partidos y movimientos políticos adhieren al voto preferente. Por esta razón, un modo de generar condiciones más propicias para una participación equitativa estaría dada por la posibilidad de que se orienten recursos a los partidos políticos y movimientos que incorporan mayormente mujeres en lugares espectables a modo de premio. También a aquellos que incorporan la cuota de género en sus organizaciones políticas.

2. Otro punto relacionado con el anterior es el de promover la equidad en la competencia electoral reorientando los recursos 
a las candidaturas de mujeres (particularmente, pero no necesariamente, entre las que se presentan por primera vez y deben instalar su candidatura frente a la sociedad).

3. Establecer controles que permitan identificar a los partidos y movimientos políticos que no cumplen con los principios de organización y funcionamiento que se postulan en el artículo 1 de la Ley 1475. La apertura hacia procesos más inclusivos se produce al interior de los propios partidos políticos donde se llevan a cabo los procesos de selección de candidatos y se deciden quiénes ocuparán las candidaturas. En esta dirección, debe preverse alguna sanción para los partidos y movimientos políticos que no muestran señales de cambio.

4. Por las razones descritas en este trabajo, se considera que la incorporación de un mandato de posición (lugares espectables) es importante para visibilizar, rutinizar y naturalizar la competencia de las mujeres en los casos que los partidos y movimientos políticos escojan el voto preferente. De igual modo, para los partidos y movimientos políticos que optan por la lista cerrada y bloqueada. Los estudios indican que el mandato de posición combinado con la lista cerrada y bloqueada garantiza un acceso continuo de las mujeres a los órganos de representación.

5. Extender y hacer efectiva la aplicación de la cuota en los distritos que eligen cuatro escańos. En estos departamentos, el $30 \%$ equivale a una mujer en las listas.
Se sumarían así Cauca, César, Huila y Risaralda.

6. Las normas deben garantizar el cumplimiento del mandato representativo ganado por las mujeres. Si por alguna causa o razón las mujeres deben renunciar a su escaño una vez electas, estas deben ser reemplazadas por candidatas del mismo sexo.

\section{REFERENCIAS}

Archenti, N. (2002). Los caminos de la inclusión política. Acciones afirmativas de género. En Vázquez, S. (comp.). Hombres públicos, mujeres públicas. Buenos Aires: Fundación Friedrich Ebert.

Archenti, N. y Tula, M. I. (2008). Mujeres y politica en América Latina. Sistemas electorales y cuotas de género. Buenos Aires: Heliasta.

Archenti, N. y Tula, M. I. (2010). (Des) Igualdad de género en las listas partidarias. Argentina 2007. En Ansaldi, W., Funes, P. y Villavicencio, S. (comps.). Bicentenario, otros relatos. Buenos Aires: Instituto de Investigaciones Gino GermaniInstituto de América Latina y el Caribe, Editores del Puerto.

Archenti, N. y Tula, M. I. (2011). Ciudadanía y representación. A 20 años de la Ley de Cuotas de Género. Revista Sociedad (29/30); Revista de la Facultad de Ciencias Sociales.

Archenti, N. y Tula, M. I. (2014). Cambios normativos y equidad de género. De las cuotas a la paridad en América Latina. Los casos de Bolivia y Ecuador. En América Latina Hoy; Revista de Ciencias Sociales de la Universidad de Salamanca (66), 47-68. 
Caul, M. (1999). Women's Representation in Parliament: The Role of Political Parties. Party Politics, 5, 79-98.

Cardozo García, F. y Quintero Benavides, A. (2014). Colombia al final de la ola: la implementación del sistema de cuotas electorales y su impacto en la participación política de las mujeres. En Archenti, N. y Tula, M. I. (coords.). La representación imperfecta. Logros y desafios de las mujeres politicas. Buenos Aires: Eudeba.

Cobo, R. (2009). Otro recorrido por las ciencias sociales: género y teoría crítica. En Aparicio García, M. y Leyra Fatou, B. (eds.). Cuadernos de Género: políticas y acciones de género. Materiales de formación. Madrid: Instituto Complutense de Estudios Internacionales, Universidad Complutense de Madrid.

Córdoba Ruiz, P. (2002). Estudios de caso: mujeres en el Congreso de Colombia. En IDEA Internacional, Serie Manuales. Mujeres en el Parlamento. Más allá de los números. Estocolmo: IDEA Internacional.

García Prince, E. (2012). La participación politica de las mujeres en Venezuela: situación actual y estrategias para su ampliación. Seminario La participación política de las mujeres en Venezuela, Desafíos y Propuestas, Cepal.

Htun, M. y Jones, M. (2002). Engendering the right to participate in decisión-making electoral quotas in women's leadership in Latin America. En Craske, N. y Molineux, M. Gender and the politics of rights and democracy in Latin America (pp. 32.56). London: Palgrave.

Johnson, N. (2014). Las barreras que la cuota no superó: selección de candidaturas y desigualdades de género en América Latina. En Archenti, N. y Tula, M. I. (coord.). La representación imperfecta.
Logros y desafios de las mujeres políticas. Buenos Aires: Eudeba.

Jones, M. P. (2000). El sistema de cuotas y la elección de las mujeres en América Latina: el papel fundamental del sistema electoral. En Saavedra Ruiz, P. (ed.). La democracia paritaria en la construcción europea (pp. 35-46). Madrid: Celem.

Katz, R. (1986). Intraparty preference voting. En Grofman, B. y Lijphart, A. (eds.). Electoral Laws and their Consequences (pp. 85-103). New york: Agathon Press.

Krook, M. L. (2006). Quotas for women in politics. Gender and candidate selection reform worldwide. Oxford: Oxford University Press.

Krook, M. L. (2008). La adopción e impacto de las cuotas de género. Una perspectiva global. En Ríos Tobar, M. (ed.). Mujer y politica. El impacto de las cuotas de género en América Latina. Santiago de Chile: PNUD.

Larserud, S. y Taphorn, R. (2007). Diseño para lograr la igualdad. Combinaciones más idóneas, medianamente idóneas y no favorables de los sistemas electorales y cuotas de género. Estocolmo: IDEA Internacional.

León, M. y Holgín, J. (2005). La cuota sola no basta. El caso de Colombia. En León, M. (ed.). Nadando contra la corriente. Mujeres y cuotas politicas en los paises andinos. Bogotá: UNIFEM/UnFPA/Universidad Nacional/IEP/CIDEM/FLACSO.

Madriz Sotillo, J. M. (2012). Visibilización de la mujer en la República Bolivariana de Venezuela. Revista Derecho Electoral (13), 318-335. Recuperado de: http://www.tse.go.cr/revista/art/13/jhannet_madriz.pdf

Marx, J., Borner, J. y Caminotti, M. (2007). Las legisladoras. Cupos de género y politica en Argentina y Brasil. Buenos Aires: Siglo xxI. 
Nohlen, D. (1994). Sistemas electorales y partidos politicos. México: Fondo de Cultura Económica.

Norris, P. (1985). Women's Legislative Participation in Western Europe. West European Politics, 8 (4), 90-101.

Norris, P. y Lovedunski, J. (eds.) (1993). Gender and Party Politics. London: Sage.

Organización de los Estados Americanos (OEA) (2014). Informe de Observación Electoral. Colombia: OEA. Ortega Gómez, B. A. y Camargo Toledo, G. N. (2012). La nueva ley de cuotas en Colombia. El caso de las Asambleas Departamentales 2007-2011. En Wills Otero, L. y Batlle, M. (comps.). Politica y Territorio. Análisis de las elecciones subnacionales de Colombia, 2011. Bogotá: PNud-Idea Internacional-NIMD.

Peschard, J. (2004). El sistema de cuotas en América Latina: panorama general. En International IDEA. La aplicación de las cuotas: experiencias latinoamericanas. Lima: IDEA.
Puyana, J. (2012). Las reformas políticas en Colombia 2003-2011: ¿hacia partidos más responsables? En Wills Otero, L. y Batlle, M. (comps.). Politica y Territorio. Análisis de las elecciones subnacionales de Colombia, 2011. Bogotá: PNUD-Idea Internacional-NIMD.

Rule, W. (1987). Electoral Systems, Contextual Factors and Women's Opportunity for Election to Parliament in Twenty-Three Democracies. Western Political Quarterly 40 (3), 477-498.

Sartori, G. (1990). Teoría de la Democracia. En: Los problemas clásicos. Buenos Aires: REI.

Schmidt, G. (2014). Disparidad de género en las reelecciones: los ciclos electorales 2006 y 20102011 en el Perú. En: Archenti, N. y Tula, M. I. (coords.). La representación imperfecta. Logros y desafios de las mujeres politicas. Ciudad de Buenos Aires: Eudeba. 